\title{
Renal vein thrombosis in Chinese patients with systemic lupus erythematosus
}

\author{
Ning-Sheng Lai, Joung-Liang Lan
}

\begin{abstract}
Objectives-To evaluate the risk factors associated with renal vein thrombosis (RVT) in Chinese patients with systemic lupus erythematosus (SLE).

Methods-Data on clinical symptoms, renal biopsy, antiphospholipid antibody syndrome profile, and serological examinations of lupus features were examined retrospectively in six patients with RVT confirmed by angiography from a total of 625 patients with SLE over a 14 year period (1982-1996).

Results-The lupus patients with RVT did not have acute symptoms of severe flank pain, haematuria, and oligouria. In contrast, most patients were suspected to have RVT because of peripheral oedema and worsening proteinuria. Roentgenological examinations (including renal sonography, renal computer tomography, or renal Doppler, or all three) were positive only in some patients. Positive antiphospholipid antibody profiles were found in four of six lupus patients. By renal biopsy, only two samples were confirmed as World Health Organisation (WHO) class $V$ lupus membranous glomerulonephritis. The others were class IV in three patients, and class III in the remaining one. No RVT was found in lupus patients without nephrotic syndrome. Peripheral thrombophlebitis was, however, noted in only one patient. Conclusion-Nephrotic syndrome could be a distinct risk factor in the development of RVT in Chinese SLE patients, in contrast with that reported in white populations in whom the peripheral thrombotic events were recognised as a determining factor.
\end{abstract}

(Ann Rheum Dis 1997;56:562-564)

Renal vein thrombosis (RVT) in systemic lupus erythematosus (SLE) is rare ${ }^{1}$ and its pathogenesis is still to be determined. Multiple factors might be indicated, including nephrotic syndrome, ${ }^{2}$ membrane glomerulonephritis, ${ }^{3}$ hypercoagulation status, ${ }^{45}$ and anticardiolipin antibody (ACA). ${ }^{67}$ Antecedent thrombophlebitis was considered to be a high risk in developing RVT or inferior vena cava thrombosis in white patients with lupus. ${ }^{8}$ It is of interest that thrombophlebitis has been less frequently observed in Chinese lupus patients. Moreover, the frequency of postoperative and oestrogen related thrombophlebitis in Chinese patients is rare, compared with those in a white population (unpublished data in Taichung and ChiaYi Veterans General Hospital). In this study, we observed a distinct pattern of risk factors in developing RVT in Chinese patients with SLE. No RVT was found in SLE patients without nephrotic syndrome. In contrast, only one patient had a previous history of deep vein thrombosis. Although rare in the prevalence of RVT in SLE, clinicians should be aware of this potentially treatable disease by knowing the associated risk factors, especially the relevant factors in the local area.

\section{Methods}

PATIENTS

Patients were selected retrospectively from the patient database in the rheumatology section. It was noted that there were six angiographically confirmed RVT cases from a total 625 lupus patients $(0.96 \%)$ over a 14 year period (1982-1996).

\section{STUDY DESIGN}

Clinical symptoms, antiphospholipid antibody profile (including ACA, thrombocyte count, activated partial thromboplastin time, and rapid plasma reagin) and serological data (complete blood count, blood urea nitrogen, creatinine, cholesterol, C3, C4, CH50, anti-dsDNA, creatinine clearance, and 24 hour urine protein) were collected and analysed. Patients received renal sonography, renal computed tomography, or Doppler evaluation of RVT, or all three, before angiographic evaluation. Renal biopsy was performed for WHO classification and evaluation of active and chronic index of lupus nephritis (active index: cellular proliferation, leucocyte infiltration, hyaline thrombus, necrosis/karyorrhexis, cellular crescent, and interstitial mononuclear cell infiltration. Chronic index: glomerular sclerosis, fibrous crescent, tubular atrophy, and interstitial fibrosis). ${ }^{9}$

\section{Results}

RVT was suspected in most patients because of the presence of recent development of heavy proteinuria, peripheral oedema, or concomitant antiphospholipid antibody syndrome symptoms, or all three (table 1). No obvious clinical symptoms were detected except very mild flank soreness and knocking pain in two patients during the physical examination. At the time of RVT development, active lupus features (pleural effusion, arthritis, haemolytic anaemia, vasculitis, malar rash, pericardial effusion) and/or active lupus nephritis were noted in clinical evaluation. Characteristically, 
Table 1 Clinical and laboratory data in six patients with renal vein thrombosis

\begin{tabular}{|c|c|c|c|c|c|c|c|}
\hline $\begin{array}{l}\text { Patient } \\
\text { (age) }\end{array}$ & $L N$ & $\begin{array}{l}\text { Clinical } \\
\text { symptom }\end{array}$ & APS profile & NS & Initial renal function & Previous APS symptom & $\begin{array}{l}\text { Lupus features at time of } \\
\text { RVT diagnosis }\end{array}$ \\
\hline $\begin{array}{l}\text { Patient } 1 \\
(20)\end{array}$ & $\begin{array}{l}\text { Class IV } \\
\text { AI: } 13, \text { CI: } 4\end{array}$ & $\begin{array}{l}\text { Peripheral } \\
\text { oedema } \\
\text { Flank soreness }\end{array}$ & $\begin{array}{l}\text { ACA 3.65, PLT: } \\
209 \\
\text { RPR (-), APTT } \rightarrow\end{array}$ & $\left(+, 4 \mathrm{~m}^{\star}\right)$ & $\begin{array}{l}\text { Transient GFR } \downarrow \text {, } \\
\text { ERPF } \downarrow \\
\text { Creatinine } \uparrow, \text { TP: } 3.8 \mathrm{~g}\end{array}$ & Pulmonary HT & Active lupus nephritis \\
\hline $\begin{array}{l}\text { Patient } 2 \\
(30)\end{array}$ & $\begin{array}{l}\text { Class III } \\
\text { AI: } 14, \text { CI: } 5\end{array}$ & $\begin{array}{l}\text { Peripheral } \\
\text { oedema }\end{array}$ & $\begin{array}{l}\text { ACA: 56, PLT: } 112 \\
\text { RPR (-), APTT } \uparrow\end{array}$ & $(+, 4 \mathrm{~m})$ & $\begin{array}{l}\text { BUN/Cr: normal } \\
\text { TP: } 4.1 \mathrm{~g}\end{array}$ & $\begin{array}{l}\text { Raynaud, CRAO, skin } \\
\text { ulceration, AVN, digital } \\
\text { gangrene }\end{array}$ & $\begin{array}{l}\text { Pleural effusion, arthritis, } \\
\text { haemolytic anaemia and } \\
\text { vasculitis }\end{array}$ \\
\hline $\begin{array}{l}\text { Patient } 3 \\
(25)\end{array}$ & $\begin{array}{l}\text { Class V } \\
\text { AI: } 12, \text { CI: } 5\end{array}$ & $\begin{array}{l}\text { Peripheral } \\
\text { oedema } \\
\text { Flank soreness }\end{array}$ & $\begin{array}{l}\text { ACA: } 1.12, \text { PLT: } \\
349 \\
\text { RPR (-), APTT } \rightarrow\end{array}$ & $(+, 3 \mathrm{~m})$ & $\begin{array}{l}\text { Transient GFR } \downarrow \text {, } \\
\text { ERPF } \downarrow \\
\text { Creatinine } \uparrow, \text { TP: } 4.4 \mathrm{~g}\end{array}$ & Pulmonary HT & $\begin{array}{l}\text { Arthralgia, malar rash } \\
\text { with rapid increase of } \\
\text { proteinuria }\end{array}$ \\
\hline $\begin{array}{l}\text { Patient } 4 \\
\text { (35) }\end{array}$ & $\begin{array}{l}\text { Class V } \\
\text { AI: } 16, \mathrm{CI}: 4\end{array}$ & $\begin{array}{l}\text { Peripheral } \\
\text { oedema }\end{array}$ & $\begin{array}{l}\text { ACA: } 26.2, \text { PLT: } \\
75 \\
\text { RPR (-), APTT } \rightarrow\end{array}$ & $(+, 2 \mathrm{~m})$ & $\begin{array}{l}\text { BUN/Cr: normal } \\
\text { TP: } 3.7 \mathrm{~g}\end{array}$ & $\begin{array}{l}\text { Pulmonary HT, AVN, deep } \\
\text { vein thrombosis, repeated } \\
\text { abortion }\end{array}$ & $\begin{array}{l}\text { Digital vasculitis, fever, } \\
\text { active lupus nephritis }\end{array}$ \\
\hline $\begin{array}{l}\text { Patient } 5 \\
(34)\end{array}$ & $\begin{array}{l}\text { Class IV } \\
\text { AI: } 17, \text { CI: } 5\end{array}$ & $\begin{array}{l}\text { Peripheral } \\
\text { oedema }\end{array}$ & $\begin{array}{l}\text { ACA: } 310, \text { PLT: } 60 \\
\operatorname{RPR}(+), \text { APTT } \uparrow\end{array}$ & $(+, 4 \mathrm{~m})$ & $\begin{array}{l}\text { BUN/Cr: normal } \\
\text { TP: } 5.3 \mathrm{~g}\end{array}$ & $\begin{array}{l}\text { Repeated abortion, brain } \\
\text { atrophy } \\
\text { Old lacunar infarction }\end{array}$ & $\begin{array}{l}\text { Malar rash, pericardial } \\
\text { effusion, haemolytic } \\
\text { anaemia }\end{array}$ \\
\hline $\begin{array}{l}\text { Patient } 6 \\
\text { (39) }\end{array}$ & $\begin{array}{l}\text { Class IV } \\
\text { AI: } 11, \text { CI: } 7\end{array}$ & $\begin{array}{l}\text { Peripheral } \\
\text { oedema }\end{array}$ & $\begin{array}{l}\text { ACA: } 22.4, \text { PLT: } \\
43 \\
\text { RPR (-), APTT } \rightarrow\end{array}$ & $(+, 2 \mathrm{~m})$ & $\begin{array}{l}\text { Cr: } 6.2 \text {, Acute renal } \\
\text { failure, TP: } 4.1 \mathrm{~g}\end{array}$ & Multiple cerebral infarction & $\begin{array}{l}\text { Synovitis, fever, malar } \\
\text { rash }\end{array}$ \\
\hline
\end{tabular}

LN: Lupus nephritis, classified according to WHO criteria; APS: antiphospholipid antibody syndrome; NS: nephrotic syndrome ; ACA: anticardiolipin antibody, IgG subclass, with normal range 15 GPL unit/ml; CRAO: central retinal artery occlusion; AVN: avascular necrosis; $\uparrow$, $\downarrow$, $\rightarrow$ : increased, decreased, and normal range, respectively; PLT: platelet count, platelet count $\times 10^{3} / \mu 1$; ERPF: effective renal plasma flow, determined by scintigraphy; GFR: glomerular filtration rate; TP: 24 hours total urine protein; AI: active renal biopsy index; CI: chronic index, Cr: creatinine; RPR: rapid plasma reagin. ${ }^{\star}$ Duration of a previous nephrotic syndrome history (months) before diagnosis of renal vein thrombosis.

all patients had nephrotic syndrome with a mean duration of antecedent nephrotic syndrome history for 3.2 months (range 2-4). A renal biopsy, performed at the time of diagnosis of RVT, showed WHO class V lupus membranous glomerulonephritis in two patients, class IV in three patients, and class III in one patient. In addition, microthrombosis in glomerulus were also identified in patients 4 and 5. Evaluation of renal function showed transient abnormality with increase in serum creatinine and decrease in the renal glomerular filtration rate in patient 1 and 3. Patient 6, however, had acute renal failure and needed haemodialysis twice. The serum creatinine decreased from $6.2 \mathrm{mg} / \mathrm{dl}$ and was maintained at $3.9 \mathrm{mg} / \mathrm{dl}$ after the start of treatment. All our lupus patients with RVT were women.

\section{ANTIPHOSPHOLIPID ANTIBODY SYNDROME}

PROFILE EVALUATION

Four patients showed a positive antiphospholipid syndrome profile (table 1). Previous thrombotic events (pulmonary hypertension, skin ulceration, retinal vessel thrombosis formation, avascular necrosis, deep vein thrombosis, repeated abortion, brain atrophy, and lacunar infarction) were noted in many of our RVT patients. These episodes were considered to be related to antiphospholipid antibody syndrome although patients with ischaemic necrosis of hip joints and pulmonary

Table 2 Roentgenological evaluation and treatment in six patients with renal vein thrombosis

\begin{tabular}{lllllll}
\hline Patient & Age $(y)$ & $\begin{array}{l}\text { Renal } \\
\text { sonography }\end{array}$ & Renal CT & $\begin{array}{l}\text { Renal } \\
\text { Doppler }\end{array}$ & RVT & Treatment \\
\hline 1 & 20 & Normal & Normal & Normal & Bilateral & C \\
2 & 30 & Normal & NP & Normal & Left & H+C \\
3 & 25 & Left $\dagger$ & Normal & Normal & Left & C, Urokinase \\
4 & 35 & Left & NP & NP & Right & C \\
5 & 34 & Normal & Engorged renal vein & NP & Left & H+C \\
6 & 39 & Normal & Engorged renal vein & Normal & Bilateral & C \\
\hline
\end{tabular}

NP: not performed; C: coumadin $5 \mathrm{mg}$ daily; $\mathrm{H}$ : heparin; urokinase: $10000 \mathrm{U} / \mathrm{h}$ for continuous 120 h; RVT: renal vein thrombosis. *Angiography finding: bilateral cortex filling defect in proximal small vein in patient 1 ; post-capillary venous obstruction over upper pole of left kidney in patient 2, multiple filling defects over lower pole of left kidney in patient 3; post-venous thrombosis over lower pole of right kidney in patient 4 ; left renal vein thrombosis with engorged renal size enlargement, $138 \mathrm{~mm}, 142 \mathrm{~mm}$ in patient 3 and patient 4 , respectively. hypertension had used prednisolone before distinct diagnosis were made. Peripheral thrombophlebitis was, however, noted in only one patient (patient 4). Data on blood components that might affect thrombotic tendency in patients such as antithrombin III, protein C, protein $\mathrm{S}$ or fibrinogen were not available in this retrospective study. No patient had used oral contraceptives at the time of development of RVT.

DIAGNOSIS OF RVT

RVT was verified in all patients by selective renal venography (table 2). Two of six patients had a kidney enlargement in the evaluation of renal sonography (patients 3, 4). Renal computed tomography evaluation disclosed a renal vein engorgement in two of four patients (patients 5,6). Renal Doppler before intervention angiography showed unremarkable findings in four of four patients. RVT was bilateral in two patients (patient 1 and patient 6) and unilateral in the other four patients (left renal vein 3, right renal vein 1). Small thrombus formation at very small branches were found in most patients with extension to the large renal vein in patients 5 and 6 . Neither inferior vena cava nor renal artery thrombosis were found. There were no associated complication of pulmonary embolism during the clinical course.

\section{Discussion}

Since the 1950s, numerous studies of renal biopsy in patients with SLE have been done in an attempt to define its pathological features and to determine the prognostic value of the pathological findings. The intrarenal vascular changes in patients with SLE have, however, received little attention. A recent study of clinicopathological necropsy data of vascular changes in the kidneys of 100 patients with SLE has shown that vascular changes (necrotising arteritis, mucinous intimal thickening, and RVT) seen in patients with SLE often modify the clinical course. The incidence of RVT was almost $2 \% .^{1}$ The findings from Kant suggest that glomerular thrombi 
occur frequently and are a singularly important factor in determining whether glomerulosclerosis develops subsequently. ${ }^{10}$ Although rare, the intrarenal vascular changes may be responsible for the sudden deterioration of renal function in some lupus patients, factors that cannot be explained by the presence of lupus glomerulonephritis alone. Clinically, early reports of RVT emphasised the presence of flank pain, microscopic haematuria, flank tenderness, rapid deterioration of renal function, and worsening of proteinuria. ${ }^{11}$ However, Harrison et al in 1956 described two groups of patients with RVT. ${ }^{12}$ The first group had a sudden onset of the above mentioned symptoms, while the second group had only the nephrotic syndrome and absence of any acute symptoms. The only clinical manifestation in these patients was peripheral oedema. Our patients belonged to the second group of RVT, with predominant clinical symptoms of nephrotic syndrome as classified by Harrison et al. High suspicion is essential for early diagnosis of this potentially treatable condition.

In a large scale evaluation of the risk factors in developing RVT in SLE patients, ${ }^{8}$ the results showed that SLE patients with peripheral thrombophlebitis had a high risk of developing RVT (61.5\%). Patients with nephrotic syndrome have a smaller risk $(27 \%)$. In their study, RVT in SLE patients who have nephrotic syndrome is just as frequent as in patients who have nephrotic syndrome of other aetiology. Our data, on the contrary, delineate a different clinical picture in Chinese SLE patients with RVT. It might be indicated that RVT in SLE patients was related to nephrotic syndrome, regardless of renal histopathological type. Furthermore, four patients had a positive antiphospholipid antibody syndrome profile at the time of diagnosis of RVT. Whether or not these ACA played a part in the development of RVT was not confirmed definitely. The reason for this disparity is still unknown, but ethnic difference (white versus Chinese), study design (prospective versus retrospective) are all possible.

RVT is frequently reported to be associated with membranous glomerulonephritis. ${ }^{13}$ The earliest findings showing that RVT occurred only in membranous glomerulonephritis led to the suggestion that RVT was the primary event in causing membranous glomerulonephritis and nephrotic syndrome by releasing renal tubular antigens. In contrast with this view, after a review of all the cases with nephrotic syndrome, Dr Zucchelli provided the tentative conclusion that RVT does not occur exclusively with membranous glomerulonephritis, ${ }^{14}$ even though the prevalence seems to be more common in membranous glomerulonephritis. In this study, RVT was found both in WHO class V, class III, and class IV lupus nephritis. Therefore, in agreement with Zucchelli, our data suggest that RVT is caused by nephrotic syndrome, particularly when complicated with increased blood viscosity, hypercoagulation state resulting from nephrotic syndrome (increased protein synthesis, including coagulation factors, and/or increased urinary loss of anti-thrombotic proteins such as anti-thrombin III during nephrotic syndrome), ${ }^{5}$ intravascular volume depletion, and other treatments such as high dose corticosteroid use. Although the retrospective nature of the study and the lack of detail information about the background SLE and RVT population weakens conclusions made about pathogenesis of RVT in this population, it is important to recognise these triggering factors in the treatment of RVT in SLE patients.

1 Tsumagari T, Fukumoto S, Kinjo M, Tanaka K. Incidence and significance of intrarenal vasculopathies in patients with systemic lupus erythematosus. Human Pathol 1985; 16:43-9.

2 Gerald BA, Gail SW, Jay IM, Conrad LP. Renal vein thrombosis, nephrotic syndrome and systemic lupus erythematosus. Ann Intern Med 1966;85:310-7.

3 Cagnoli L, Viglietta G, Madia G, Gattiani A, Orsi C, Rigotti A, et al. Acute bilateral renal vein thrombosis superimA, et al. Acute bilateral renal vein thrombosis superimposed on calcified thrombus of the inferior vena cava in a
patient with membranous lupus nephritis. Nephrol Dial patient with membranous lupu
Transpl 1990;suppl 1:71-4.

4 Llach F. Hypercoagulability, renal vein thrombosis, and other thrombotic complications of nephrotic syndrome. Kidney Int 1985;28:429-39.

5 Kanfer A. Coagulation factors in nephrotic syndrome. A J Nephrol 1990;10 (suppl 1):63-8.

6 Ronald AA, Neil B, Elaine B, Graham RVH. Postpartum bilateral renal vein thrombosis in the primary antiphospholipid syndrome. J Rheumatol 1993;20:874-6.

7 Liu WH, Lan JL, Chen DY, Wei HL, Lai NS. Renal vein thrombosis in Chinese systemic lupus erythematosus with high titers anticardiolipin antibody. Br J Rheumatol 1992; 31:787-8.

8 Gregorio M, Eduardo AV, Gaspar GE, Francisco AG. Renal vein thrombosis and inferior vena cava thrombosis in systemic lupus erythematosus. Arthritis Rheum 1984; 27:539-44.

9 Austin HA, Muenz LR, Joyce KM, Antonovych TT, Balow JE. Diffuse proliferative lupus nephritis: identification of specific pathologic feature affecting renal outcome. specific pathologic feature
Kidney Int 1984;25:689-95.

10 Kant KS, Pollak VE, Weiss MA, Glueck HI, Miller MA, Hess EV. Glomerular thrombosis in systemic lupus erythematosus: prevalence and significance. Medicine $1981 ; 60: 71-86$.

11 Rayer PRO. Traite des maladies des reins et des alterations de la secretions urinaire. Vol 2. Paris: J B Balliere, 1940: 590-9.

12 Harrison CV, Milne MD, Steiner RE. Clinical aspect of renal vein thrombosis. Q J Med 1956;25:285-98.

13 Trew PA, Biava CG, Jacobs RP. Renal vein thrombosis in membranous glomerulonephropathy: incidence and association. Medicine 1978;57:69-74

14 Zucchelli P. Renal vein thrombosis. Nephrol Dial Transpl 1992; suppl 1:105-8. 